\title{
Installing artificial macropores in degraded soils to enhance vertical infiltration and increase soil carbon content
}

\author{
Yasushi Mori $^{{ }^{*}}$, Atsushi Fujihara ${ }^{2}$ and Kazuto Yamagishi ${ }^{2}$
}

\begin{abstract}
Of all terrestrial media (including vegetation and the atmosphere), soil is the largest store of carbon. Soils also have important functions such as water storage and plant support roles. However, at present, these characteristics do not fully function, because of, for example, climate-change-induced heavy rainfall would wash away the organic-rich surface soils. In this study, artificial macropores were introduced into exposed soil plots for the purpose of enhancing infiltration, and fibrous material was inserted to reinforce the macropore structure. As expected, the capillary force caused by the fibers drew surface water deeper into the soil profile before saturation. Additionally, the same capillary force promoted vertical transport, while micropores (matrix) enhanced horizontal flow. Our results show that infiltration was more effective in the fiber-containing macropores than in empty macropores. Additionally, our column experiments showed that artificial macropores reduced surface runoff when the rainfall intensities were 2,4 , and $20 \mathrm{~mm} \cdot \mathrm{h}^{-1}$ but not for $80 \mathrm{~mm} \cdot \mathrm{h}^{-1}$. In field experiments, soil moisture sensors installed at depths of 10,30, and $50 \mathrm{~cm}$ responded well to rainfall, showing that artificial macropores were able to successfully introduce surface water into the soil profile. One year after the artificial macropores were installed, a field survey carried out to assess soil organic matter and plant growth showed that plant biomass had doubled and that there was a significant increase in soil carbon. This novel technique has many advantages as it mimics natural processes, is low cost, and has a simple structure.
\end{abstract}

Keywords: Macropore; Infiltration; Soil degradation; Carbon sequestration

\section{Background}

Soil, the largest of all terrestrial carbon stores, contains as much as three times the amount of carbon stored in vegetation and two times that stored in the atmosphere (Eswaran et al. 1993). Soils also have important functions such as water storage and plant support roles. However, at the present time, these soil capabilities are progressively being weakened because of climate change (IPCC 2013). Meteorological measurements have shown that, in the last 30 years, heavy rainfall events in excess of $50 \mathrm{~mm} \cdot \mathrm{h}^{-1}$ have increased in Japan (The Japan Meteorological Agency 2013). Such heavy rains sometimes produce a crust or hardpan at the soil surface, which degrades infiltration. This, in turn, increases the risk of

\footnotetext{
* Correspondence: yasushim@cc.okayama-u.ac.jp

1 Graduate School of Environmental and Life Science, Okayama University,

3-1-1 Tsushimanaka, Okayama 700-8530, Japan

Full list of author information is available at the end of the article
}

soil erosion, even in temperate zones, where the climate is generally moderate.

In addition to the increased number of heavy rainfall events, the amount of improperly managed agricultural land in Japan is increasing because of manpower limitations caused by an aging society (Ministry of Agriculture, Forestry and Fisheries 2011; Oohara 2007). Land use makes a crucial contribution to the hydrological cycle, but it can be strongly influenced by management practices. For example, soil erosion may occur in abandoned agricultural fields (Osawa et al. 2004a, 2004b), and bare ground is often visible in forest plantations when thinning operations have been delayed (Miyamoto et al. 2013), as well as in areas where sunlight is blocked and understory vegetation is rare (Kiyono 1988; Yukawa and Onda 1995). In such settings, the infiltration rate may be low and organic matter content decreases sharply with profile depth.

Enhancing soil infiltration would increase both its water-retention capacity and its organic matter content. 
In the soil and agricultural sciences, infiltration improvement usually involves cultivation to soften the surface soils. However, cultivation can dry the soils, and heavy rainfall can wash away organic-rich surface layers (Osawa et al. 2004a, 2004b. Therefore, since cultivation or surface soil softening is often a suboptimal choice for restoring illdrained soils, this study examines a method for improving soil infiltration without cultivation.

Macropores are naturally occurring continuous apertures such as wormholes, root channels, or inter-aggregate pores. In general, macropores are notorious for causing bypass flow and interfering with the proper use of applied chemicals because their irregular structures make it hard to produce accurate estimates based on infiltration theory, which assumes that soil is an isotropic material (e.g., Beven and Germann 1982). However, recent experimental evidence suggests that preferential flow tends to be the rule rather than the exception under field conditions (Flury 1996). Moreover, by promoting intensive flows of water and nutrients, soil macropores have been recognized as a food source for soil microflora and fauna (Angers and Caron 1998). Based on the above, we decided to explore macropore characteristics in order to determine how they contribute to water and solute transport in soils.

To date, many authors have studied the characteristics of root channels or macropores. Although natural soil pore structures may seem irregular, if examined in detail, it is clear that their structures develop in an orderly manner. In macro-porous soils, the solute infiltration region drastically changes when the water content and boundary conditions for infiltration change (Mori et al. 1999a, 1999b, 2001). For example, when a soil column was saturated (suction $=0 \mathrm{kPa}$ ) water was preferentially introduced into macropores (Mori et al. 1999a). Additionally, when the infiltration velocity was maintained at $1 / 10$ of the saturated hydraulic conductivity and the matric potential at the matrix was maintained at $-3 \mathrm{kPa}$, (empty) macropore bypass flow disappeared and solutes were distributed throughout the whole soil body (Mori and Higashi 2009). Therefore, artificial macropores were created to facilitate effective vertical infiltration. However, empty artificial macropores were found to clog easily, which prevents infiltration from continuing for prolonged periods (Mori and Hirai 2014). Subsequently, thin section observations showed that natural macropore walls were coated with clay, organic matter, and natural polymers (Mori et al. 1999b) and that since empty artificial macropores do not have these coatings, they are easily prone to clogging and collapse. Such bio-clogging was avoided when artificial macropores were filled with fibrous material, and solutes were successfully transported into the soil profile over prolonged periods (Mori and Hirai 2014). More specifically, the fiber-filled macropore structure permitted vertical infiltration, while the micropore or matrix facilitated solute distribution into the soil body, thereby achieving effective bioremediation (Mori and Hirai 2014).

In the current study, we designed artificial macropores filled with fibrous material based on what we have learned about the natural structure of soil. For example, poor drainage causes surface runoff and soil loss, which are considered to be major causes of land degradation. Therefore, we designed a method to enhance vertical infiltration of poorly drained soils, based on our belief that if bare land with poor vegetation or low soil organic matter could be improved using our infiltration technique, it would be possible to prevent surface runoff, and thus nutrients and organic matter could be successfully delivered to the whole soil body. This, in turn, would help restore the soil environment.

Accordingly, the objective of this study was to create artificial macropores in soils where poor drainage is one of the causes of land degradation and to thereby improve infiltration, increase the organic matter content, and promote vegetation growth.

\section{Methods}

\section{Design of the artificial macropore}

An example of a three-dimensional X-ray computed tomography image (InspeXio CT-90; Shimadzu, Kyoto, Japan) for natural soil is shown in Figure 1. This image was taken using the technique outlined by Mori et al.

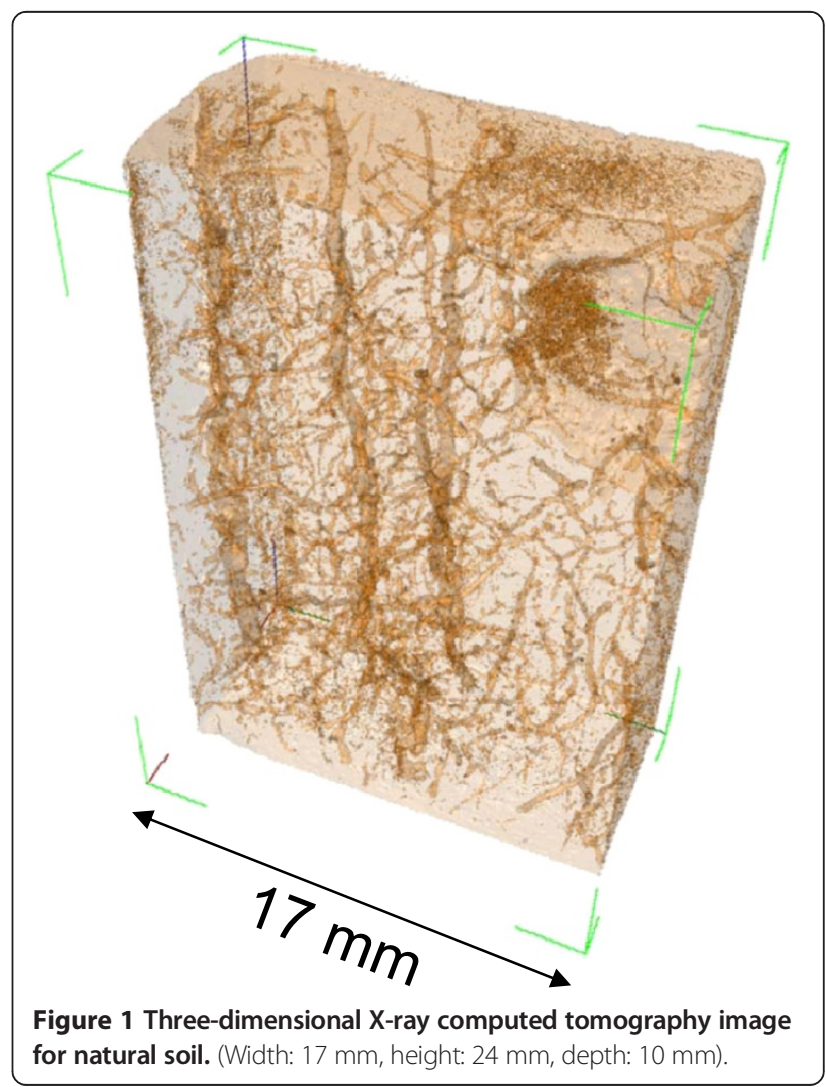


(1999a, 1999b). The soil sample was obtained from a gray lowland paddy field at a depth of $50 \mathrm{~cm}$. It is clear from this image that the pore structure extends both vertically and horizontally. These pore shapes reflect the plant roots, and macropore structures of this nature were ubiquitous in the sample.

We then attempted to improve the process of infiltration in exposed soils by creating artificial macropores that mimic the natural macropore structure. As described in our earlier study, prototype artificial macropores (Mori and Hirai 2014) can successfully deliver solutes into the whole soil body. In this paper, we designed artificial macropores (Figure 2) with the following characteristics:

a. Glass fiber, a fibrous material, was inserted into an artificial macropore to reinforce the structure in order to mimic the soil fauna wall coating that occurs in the case in natural macropores.

b. The fibrous material produced a capillary force that draws surface water downward and produces vertical infiltration.

c. The anisotropy in vertical/horizontal infiltration of fibrous material was used to effectively introduce vertical flow, which is different from pellet or powder fillings.

In this study, the fibrous material was installed so that its upper point protruded above the ground in order to help counteract flood-related problems. Specifically, it was thought that, in flood conditions, small soil particles would easily clog or encrust the macropores at the surface level, so a self-supported 1 to $2 \mathrm{~cm}$ protrusion

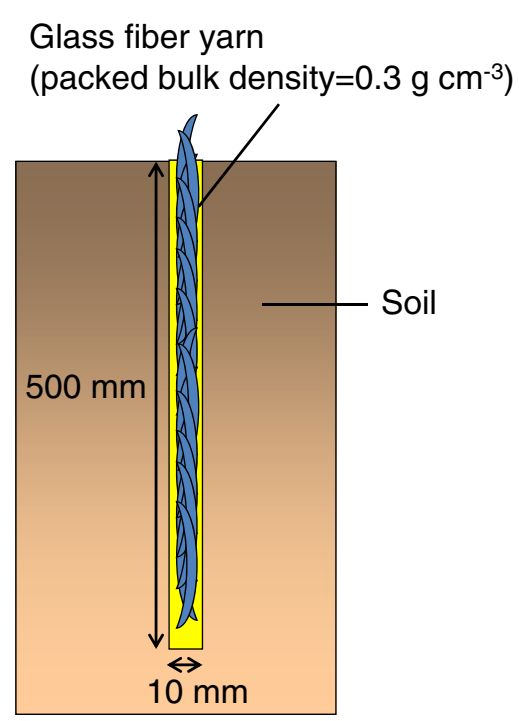

Figure 2 Schematic representation of artificial macropore. would provide a more accessible infiltration pathway to the macropores and thus draw water deeper into the soil profiles.

Figure 3 shows the designed soil water-retention curve of the examined red-yellow soils and glass fiber fillings. As can be seen in the figure, there were significant differences in water-retention capacities. Artificial macropores with glass fiber fillings had large pore volumes of 0.7 to $0.8 \mathrm{~m}^{3} \cdot \mathrm{m}^{-3}$ and released water easily when suction was applied because the pore structure was rough and large. Furthermore, there was a steep decline in water content between several to several tens of $\mathrm{cmH}_{2} \mathrm{O}$, owing to the uniform capillary pore structure produced by the fiber. However, the examined soils had lower saturated water content and did not release water easily because of their clay content. These differences in waterretention characteristics emerged at the intersection of each characteristic curve. When soil was saturated, such as after a heavy rainfall event that left water on the surface, capillary force exerted by the glass fiber would draw the surface water deeper into the soil profile. When the water content decreased and suction occurred in the soil matrix part, i.e., below the intersection point, the soil matrix played a major role in facilitating drainage. At such times, rainfall might be expected to be more effectively delivered to the soil profile, thereby avoiding surface runoff.

The double line shows the combined characteristics of the designed soil. The small volume of artificial macropores (see Figure 2) does not change the water-retention capacity of native soils, but rather, it increases the ease of infiltration without changing the water-retention capacity.

Water-retention curves were also measured for actual glass fibers and soils in order to more properly evaluate

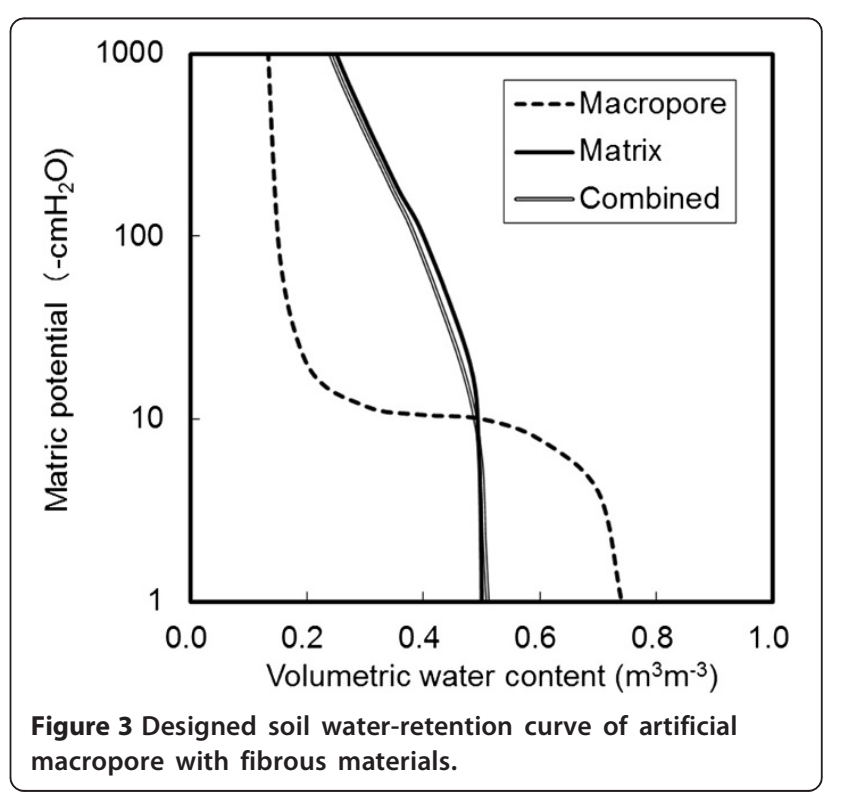


our theory. In this investigation, glass fibers and soils were independently packed into $100 \mathrm{~mL}$ core samplers, after which hanging water column experiments (Klute and Dirksen 1986) were conducted for each glass fiber and soil column in order to measure water-retention curves.

\section{Column infiltration experiment}

As a preliminary experiment, we carried out infiltration testing during which artificial rainfall was applied and the drainage capacity of the artificial macropores was evaluated. First, we collected undisturbed red-yellow soil samples in cylindrical columns $(5 \mathrm{~cm}$ in diameter and $10.2 \mathrm{~cm}$ long) from land adjacent to the Education and Research Center for Biological Resources $\left(35^{\circ} 31^{\prime} \mathrm{N}\right.$ to $\left.133^{\circ} 06^{\prime} \mathrm{E}\right)$, Shimane University, Japan, which is the site of this study. The average particle densities, porosity, and saturated hydraulic conductivities of the samples were $2.76 \mathrm{~g} \cdot \mathrm{cm}^{-3}, 0.515 \mathrm{~cm}^{3} \cdot \mathrm{cm}^{-3}$, and $7.64 \times 10^{-4} \mathrm{~cm} \cdot \mathrm{s}^{-1}$, respectively.
Figure 4 shows the experimental setup. Each soil sample was set into a pressure cell with a membrane filter $(0.5 \mu \mathrm{m})$ set at the sample bottom. A drainage tube was set so that suction of $2.4 \mathrm{kPa}$ was applied gravitationally. Next, an artificial macropore was created in the center of the column using the following procedure. First, a stainless pipe $(0.6 \mathrm{~cm}$ in diameter) was used to hollow out and remove the excessive soil. Then, the glass fiber was inserted into the gap at a packed density of $0.30 \mathrm{~g} \cdot \mathrm{cm}^{-3}$, thereby creating an artificial macropore from fibrous materials. After saturation from the bottom, soil samples were drained for $24 \mathrm{~h}$ to release the gravitational water. A membrane filter was then placed at the top of the sample to attenuate the effect of raindrop impacts, after which $200 \mathrm{~cm}^{3}$ of artificial rainfall was applied through a tube via a peristaltic pump. The rainfall intensities and durations were $2,4,20$, and $80 \mathrm{~mm} \cdot \mathrm{h}^{-1}$ and $50,25,5$, and $1.25 \mathrm{~h}$, respectively. After the rainfall, drainage water was collected for $120 \mathrm{~h}$ to ensure the soil reached equilibrium.

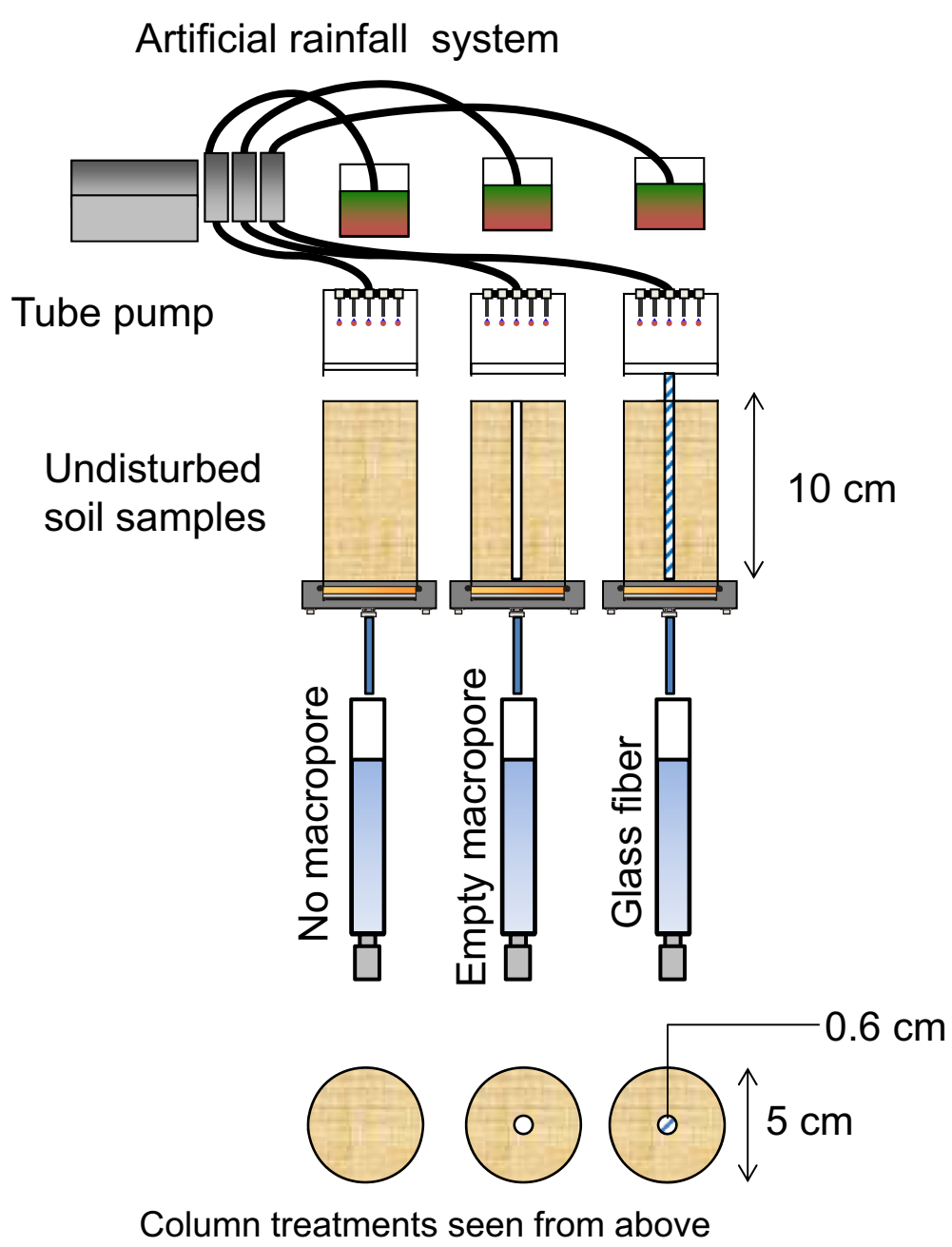

Figure 4 Experimental setup for the infiltration experiments with macropores. 


\section{Field experiment}

In this section, we explain field experiments carried out to enhance the vertical infiltration of in situ soil at the Shimane University study site, which was located on a mountain side. The characteristics of the red-yellow soil studied are described in Table 1 . These soils were sampled using a soil auger when we installed the soil moisture sensors and found to be clayey, dispersive, and poor in organic matter. Thus, when used for agriculture, additional fertilizer is highly recommended.

Flat plots $(200 \times 80 \mathrm{~cm})$ were selected for our experimental sites. Three replicate plots $(33 \times 80 \mathrm{~cm}$ each $)$ were prepared for each soil treatment, macropore and control. The vegetation was removed in July 2008, after which $50 \mathrm{~cm}$ deep artificial macropores (Figure 2) were installed $20 \mathrm{~cm}$ apart (see Figure 5). Soil moisture sensors (Hydra Probe II; Stevens Water Monitoring Systems, Inc., Portland, OR, USA) were then installed between the artificial macropores at depths of 10,30 , and $50 \mathrm{~cm}$ to monitor the infiltration effectiveness of the artificial macropores. A control area was also established to allow us to compare two treatments, macropore and control.

The experimental plots were monitored by soil moisture sensors until April 2009, after which soil samples were collected from 10, 30, and $50 \mathrm{~cm}$ depths using a soil auger in order to measure total carbon (TC). Roots were eliminated when they were observed, and TC was measured by a $\mathrm{C} / \mathrm{N}$ macro coder ( $\mathrm{CN}-1000$; J-Science Lab. Kyoto, Japan.). Plants were also sampled at the ground level $(0 \mathrm{~cm}$ depth) in order to measure plant biomass amounts. Since the plants were cut at ground level, this plant biomass did not include roots. Plant species were identified based on their morphological features, after which they were oven dried at $60^{\circ} \mathrm{C}$ to obtain their dry weight measurements.

\section{Results and discussion}

Artificial macropore characteristics

The soil water-retention curves for the artificial macropores are shown in Figure 6. When the saturation level

Table 1 Initial condition for examined soils

\begin{tabular}{|c|c|c|c|c|c|c|}
\hline \multirow[b]{4}{*}{ Depth (cm) } & \multicolumn{6}{|c|}{ Treatment } \\
\hline & \multicolumn{3}{|c|}{ Control plot } & \multicolumn{3}{|c|}{ Macropore plot } \\
\hline & $\mathrm{X} 10$ & X30 & $\times 50$ & M10 & M30 & M50 \\
\hline & 10 & 30 & 50 & 10 & 30 & 50 \\
\hline Clay (\%) & 20.9 & 23.7 & 25.1 & 20.1 & 23.8 & 23.8 \\
\hline Silt (\%) & 70.9 & 71.6 & 71.4 & 69.2 & 71.4 & 69.7 \\
\hline Sand (\%) & 8.2 & 4.7 & 3.5 & 10.7 & 4.8 & 6.5 \\
\hline WC (m3m-3) & 0.11 & 0.29 & 0.34 & 0.10 & 0.30 & 0.28 \\
\hline TC (\%) & 1.39 & 0.26 & 0.39 & 1.26 & 0.28 & 0.37 \\
\hline
\end{tabular}

VWC, volumetric water content; TC, total carbon

$\mathrm{M}$ and $\mathrm{X}$ denote macropore plot and no macropore plot (control), respectively.

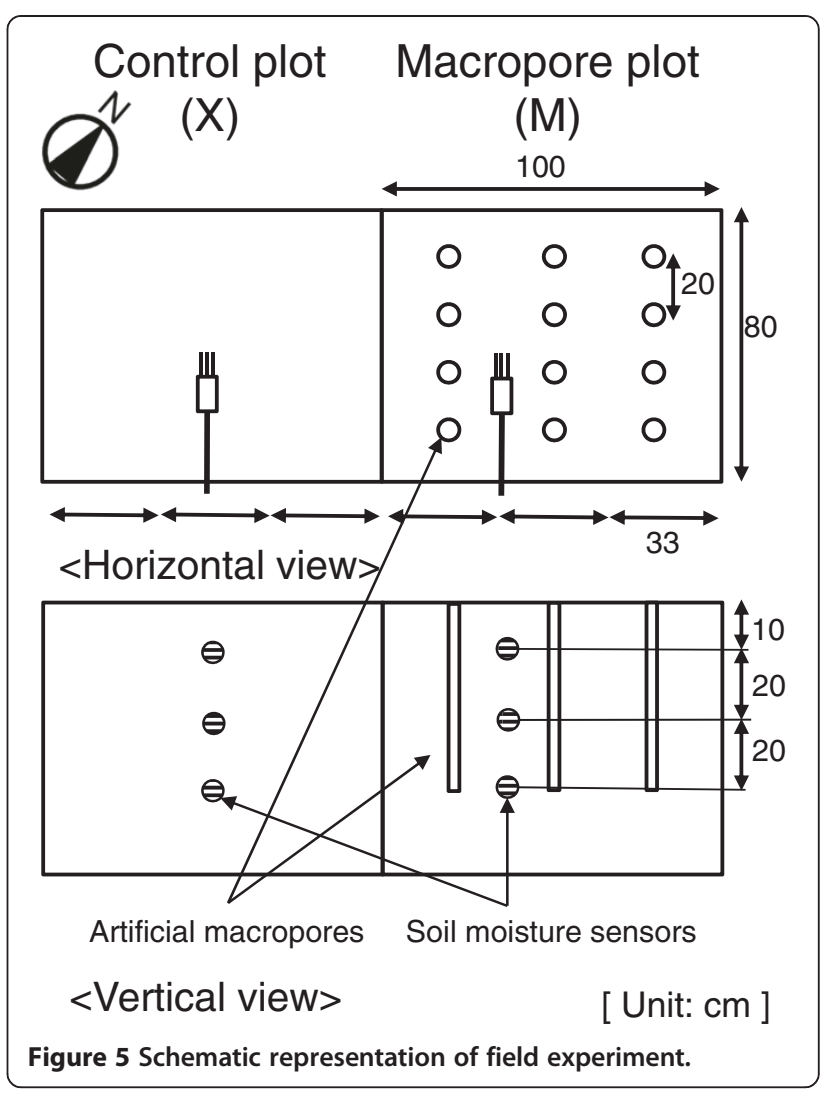

was $0.87 \mathrm{~cm}^{3} \cdot \mathrm{cm}^{-3}$, the water content of the artificial macropore corresponded well with the theoretical pore volume estimated from the solid phase ratio $\left(0.3 \mathrm{~g} \cdot \mathrm{cm}^{-1}\right)$ and glass density $\left(2.55 \mathrm{~g} \cdot \mathrm{cm}^{-3}\right)$, which is $1-(0.3 / 2.55)=$ $0.88 \mathrm{~cm}^{3} \cdot \mathrm{cm}^{-3}$. The average pore size of the glass fiber (TOMBO No.8402, NICHIAS, Tokyo, Japan) was $0.009 \mathrm{~mm}$, and thus most of the water drained

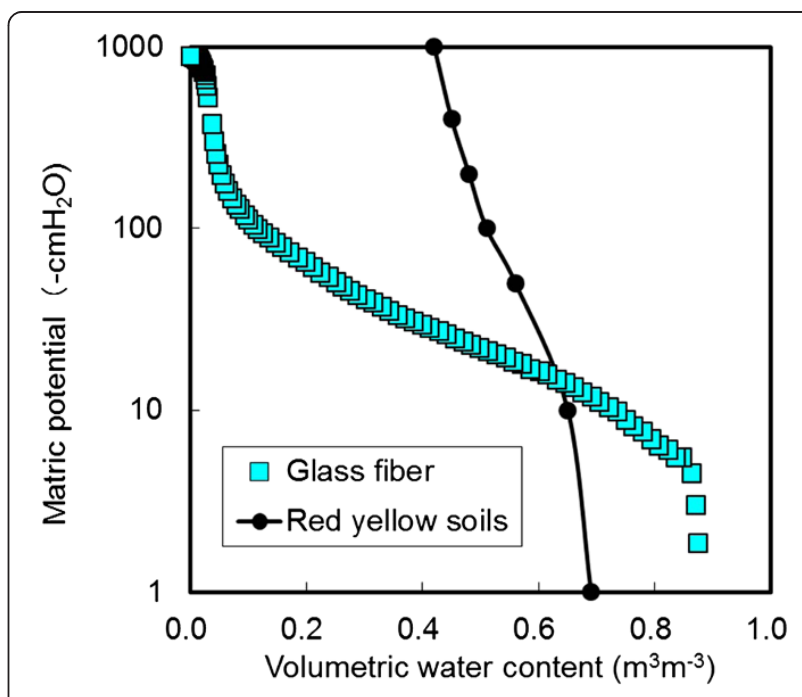

Figure 6 Soil water-retention curve of artificial macropore with glass fiber fillings. 
at $-300 \mathrm{cmH}_{2} \mathrm{O}$ of matric potential, which was estimated from the Laplace equation for capillary tubes, $\Delta P=\frac{2 \sigma}{r}$, where $\sigma$ is the surface tension for water, $\Delta \mathrm{P}$ is the potential, and $\mathrm{r}$ is the radius of the capillary. Because we used a uniform glass fiber size, the water content rapidly decreased as we applied higher suction, which corresponded well with the steep decline in the theoretical graph. Conversely, based on our estimates of the characteristics of clayey soil, the saturated water content of the red-yellow soil was less than that of the glass fiber. However, the water content did not decrease when the suction was stronger.

Although the infiltration capacity of the proposed artificial macropore system was better than that of the poorly drained soil, the system also has infiltration process advantages over natural macro-porous soil. For instance, with natural empty earthworm macropores, root macropores, or inter-aggregate macropores, there is usually a gap between the saturated and matrix infiltration levels. Thus, empty macropores introduce water when soil is saturated or when there is surface water after heavy rain. Our proposed artificial macropore system fills this hydraulic gap because the capillary force caused by a glass fiber effectively induces surface water into the soil body. Additionally, since there is an intersection between the two curves of the artificial macropore and the soil matrix, the shift in the hydraulic function will effectively enhance infiltration (see the 'Design of the artificial macropore' section for further details).

\section{Column infiltration experiment}

Table 2 shows the results of drainage/total rainfall as affected by the rainfall intensity. Evaporation was neglected for short-term experiments because it was around $1 \mathrm{~mm} \cdot \mathrm{d}^{-1}$. The red-yellow soils in this study site originally had a saturated hydraulic conductivity of $10^{-4} \mathrm{~cm} \cdot \mathrm{s}^{-1}\left(3.6 \mathrm{~mm} \cdot \mathrm{h}^{-1}\right)$. Since no macro-porous sample, including water absorption by bulk soils, would be capable of draining rainfall in excess of $4 \mathrm{~mm} \cdot \mathrm{h}^{-1}$, surface water appeared when rainfall exceeded $20 \mathrm{~mm} \cdot \mathrm{h}^{-1}$. However, the results show that the macropores improved infiltration and prevented surface runoff and that empty macropores apparently improved the drainage/total rainfall (Table 2). However, the empty macropore gradually collapsed and clogged, which is similar to what occurred in previous studies (Mori and Hirai 2014), while the glass fiber reinforced structure of the artificial macropores improved long-term infiltration (Mori and Hirai, 2014). As previously mentioned, in this study, we intentionally left the tops of the glass fiber inserts above the ground, which prevented the macropores from becoming clogged by small particles and successfully allowed drainage to continue. However, even the artificial macropore could not function effectively when rainfall was $80 \mathrm{~mm} \mathrm{~h}^{-1}$, which is significant because rainfall events of this magnitude are increasingly common (The Japan Meteorological Agency 2013).

\section{Field experiment (infiltration)}

Daily soil moisture fluctuations are shown in Figure 7 as volumetric water content, where it can be seen that the water content at $10 \mathrm{~cm}$ of depth was affected by rainfall events. The water content at $10 \mathrm{~cm}$ depth for the control plot was slightly larger than that of the macropore plot, probably because the field, in its original condition, was poorly drained and the macropore plot enhanced infiltration. Since rainfall was small during September and November, we could observe a decreasing trend in water content. In September, once infiltration water increased the water content, for which the macropore plot showed slightly larger water content than the control plot at $30 \mathrm{~cm}$ and also $50 \mathrm{~cm}$. The water content trend for $30 \mathrm{~cm}$ was found to be similar to the $10 \mathrm{~cm}$ depth, where the water content in the control plot is generally higher than in the macropore plot.

On the other hand, the water content at $50 \mathrm{~cm}$ tended to be higher in the macropore plot than in the control plot, especially after December, because the water content is affected by rainfall and our experimental plots are located in Japan's San-in region, where snow and sleet are normally heavy during the winter months. Thus, it is estimated that winter snow and sleet introduced water $50 \mathrm{~cm}$ deep via the macropores. However, the water content at $30 \mathrm{~cm}$ was larger in the control plot than in the macropore plot, even during the winter season. We conjectured, that in the control plot, rainfall was conveyed through the matrix and settled at the $30 \mathrm{~cm}$ level, while

Table 2 Differences in drainage efficiency for soil columns

\begin{tabular}{cccc}
\hline Rainfall intensity $(\mathbf{m m} / \mathbf{h})$ & \multicolumn{2}{c}{ Drainage efficiency $\left(\frac{\mathrm{drainage}}{\text { total rainfall }}\right)$} \\
\cline { 2 - 4 } & No macropore & Empty macropore & Macropore with glass fiber fillings \\
\hline 2 & 1.00 & 1.00 & 1.00 \\
4 & 1.00 & 1.00 & 0.98 \\
20 & 0.19 & 0.92 & 0.34 \\
80 & 0.08 & 0.28 & 0.08
\end{tabular}

1 means perfect drainage, while 0 means emergence of surface runoff. 

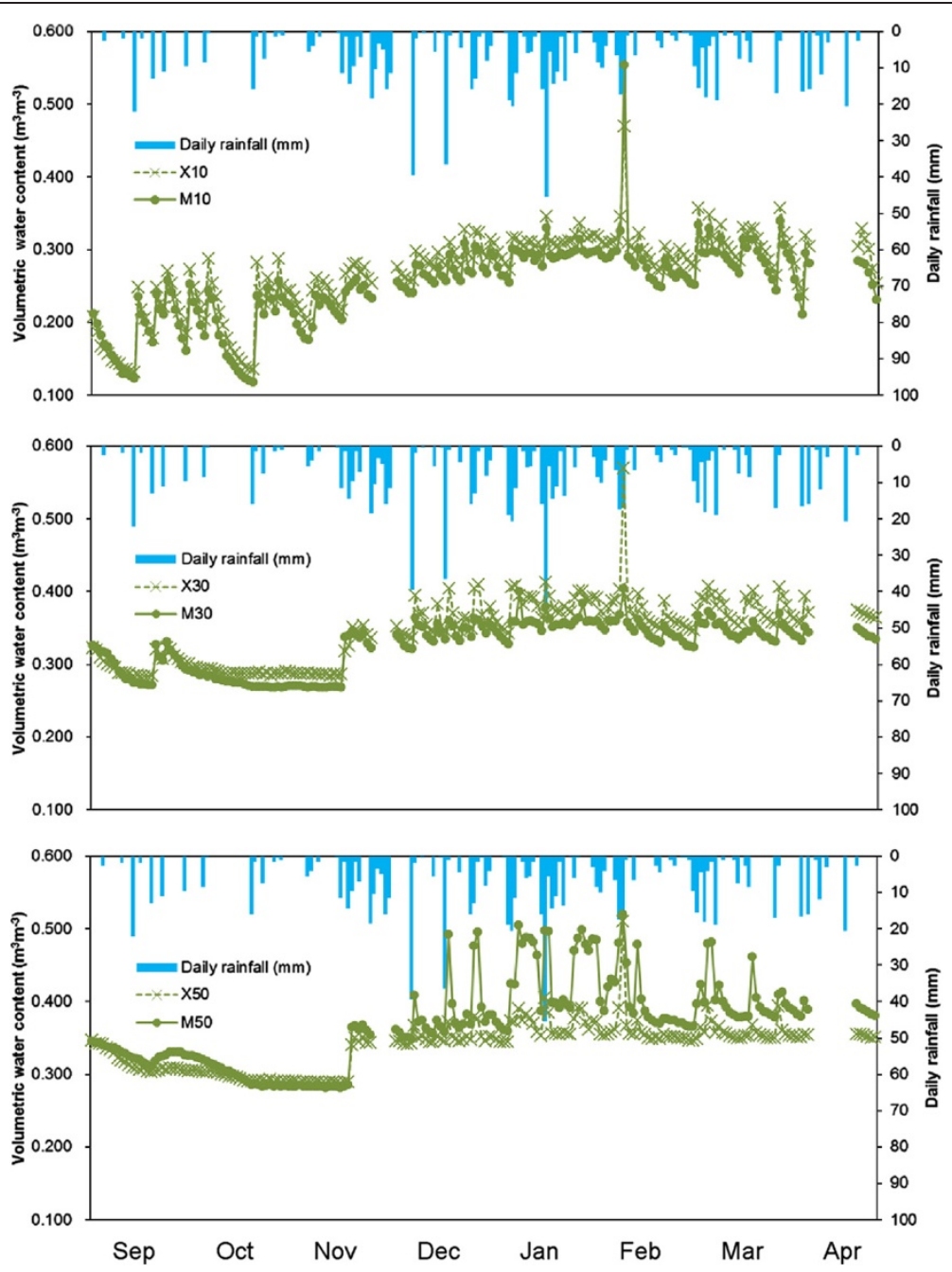

Figure 7 Daily soil moisture fluctuations $(10,30,50 \mathrm{~cm}$ depth) at control and macropore plot.

in the artificial macropore, the same rainfall bypassed the matrix and settled at $50 \mathrm{~cm}$.

Data for the three depths showed that infiltrated water was transported successfully to deeper profile depths in the macropore plot, until reaching a depth of $50 \mathrm{~cm}$. Accordingly, we concluded that our artificial macropore with fibrous material successfully induced the transport of surface water deeper into the soil profile.

\section{Field experiment (total carbon)}

Figure 8 shows the net increment in soil TC at depths of 10,30 , and $50 \mathrm{~cm}$ after the field experiments. Roots were eliminated when they were observed. When the net increment was calculated, TC was found to have increased more at 30 and $50 \mathrm{~cm}$ than at the $10 \mathrm{~cm}$ depth. In addition, we found that TC had increased more at $30 \mathrm{~cm}$ in the macropore plot than in the control plot. At this point, the thin layer of organic matter located at the degraded soil surface was expected to be induced into the

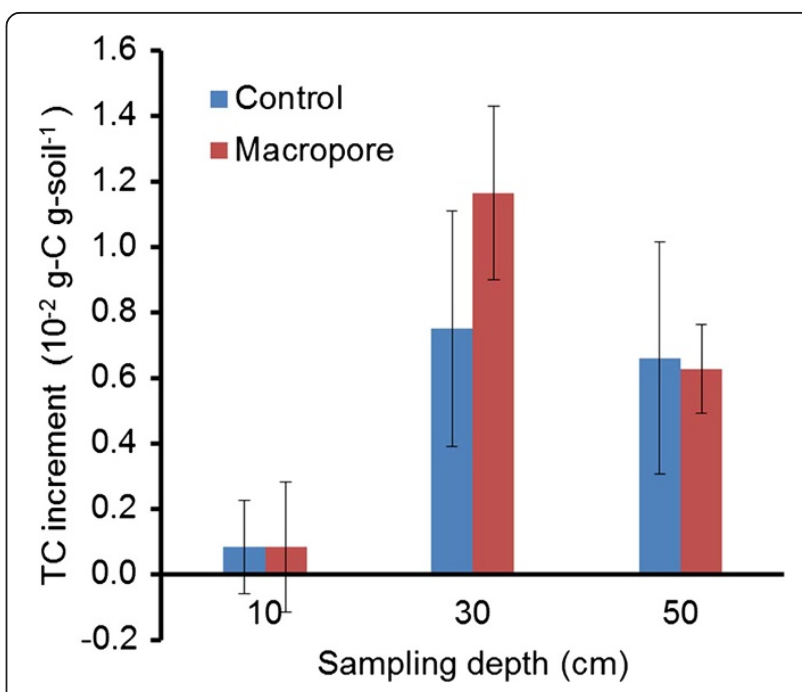

Figure 8 Net increment of soil total carbon (TC) after 1-year macropore treatment. 
soils as solution (Yamamoto 2013), thereby increasing TC at the subsurface soil layer. However, we observed a higher water content increment at the $50 \mathrm{~cm}$ depth than at other depths (Figure 7). While the reason for this is currently unclear, it may be because organic matter was filtered by the soil during the infiltration process.

Based on the results of this study, we summarized the TC increment for the vertical profile and then calculated the average TC increment for the three replicate plots. The average TC increment compared with the control plot was calculated as $0.0012 \mathrm{~g}-\mathrm{C} \cdot \mathrm{g}$-soil ${ }^{-1} \cdot \mathrm{yr}^{-1}$ for the macropore plot. This number was converted to $7.0 \mathrm{t}-\mathrm{C} \cdot \mathrm{ha}^{-1} \cdot \mathrm{yr}^{-1}$, with a bulk density of $1.1 \mathrm{~g} \cdot \mathrm{cm}^{-3}$ through the $50 \mathrm{~cm}$ depth. This TC increment was larger than the carbon increase that was reported for cultivated fields (Hillel and Rozenzweig 2009) as 0.1 to $0.7 \mathrm{t}-\mathrm{C} \cdot \mathrm{ha}^{-1} \cdot \mathrm{yr}^{-1}$ but corresponded well with the increase in pasture management (Conant et al. 2001) as 0.11 to $3.04 \mathrm{t}-\mathrm{C} \cdot \mathrm{ha}^{-1} \cdot \mathrm{yr}^{-1}$ and afforestation $\left(0.27\right.$ to $\left.9.55 \mathrm{t}-\mathrm{C} \cdot \mathrm{ha}^{-1} \cdot \mathrm{yr}^{-1}\right)$ (converted from 1 to $35 \mathrm{t}-\mathrm{CO}_{2} \cdot \mathrm{ha}^{-1} \cdot \mathrm{yr}^{-1}$, IPCC 2007) The number is also reasonable because this technique introduced surface organic matter into a deeper profile as solution (Yamamoto 2013) while stimulating plant shoot growth through enhancing infiltration.

Although this first result is relatively large, such increments cannot be expected to continue indefinitely as degraded soil will tend to approach a state of $\mathrm{C}$ equilibrium (or $\mathrm{C}$ saturation) in a short time. The research results showed that ill-drained, nutrient-poor soils could be significantly restored simply through enhancing infiltration. Another advantage of this technique is that enhanced infiltration was achieved without cultivation or turnover. While these are common agricultural practices used to improve infiltration, cultivation breaks soil aggregates into particles and exposes the broken soil to dry air. This, in turn, can result in loss of fine particles or erosion. In our experiment, a glass fiber was used to modify the soil characteristics and enhance infiltration without cultivation or turnover.

\section{Field experiment (plant biomass)}

Figure 9 shows the vegetation in April 2009 after field application of the artificial macropores. In this photograph, the macropore plot is shown on the left side, while the control plot is shown on the right. The deep green color seen in the macropore plot indicates that vegetation was more abundant in the macropore plot, even though it was small in the control plot. Additionally, most of the vegetation in the control plot consisted of small short-rooted plants, while tall deep-rooted plants were observed in the artificial macropore area. The collected plant species are listed in Table 3. The number for Nigra, a Vicia sativa subsp. (Numata and Yoshizawa 1978), which grows in well-drained soils, was significantly larger in the macropore plot than in the control plot. Conversely, Cardamine scutata, Capsella bursa-pastoris (Numata and Yoshizawa 1978), which will grow even in poorly drained soils, were larger in the control plots than in the macropore plots.

Plants from all three replicate plots were sampled, and their weights were measured and compared with the control plots. It was found that the amount of plant biomass was $85.3 \%$ larger in the macropore plots than the control plots (Figure 10). Assuming that seeds were distributed evenly in these plots after the preliminary cutting prior to this experiment, the enhanced vertical infiltration of water, nutrients, organic matter, and oxygen (Mori et al. 2013) improved the suitability of the growth environment and resulted in larger and more deep-rooted plants.

It is noteworthy that we started this experiment with the aim of enhancing vertical infiltration and introducing surface organic matter into a soil body that would

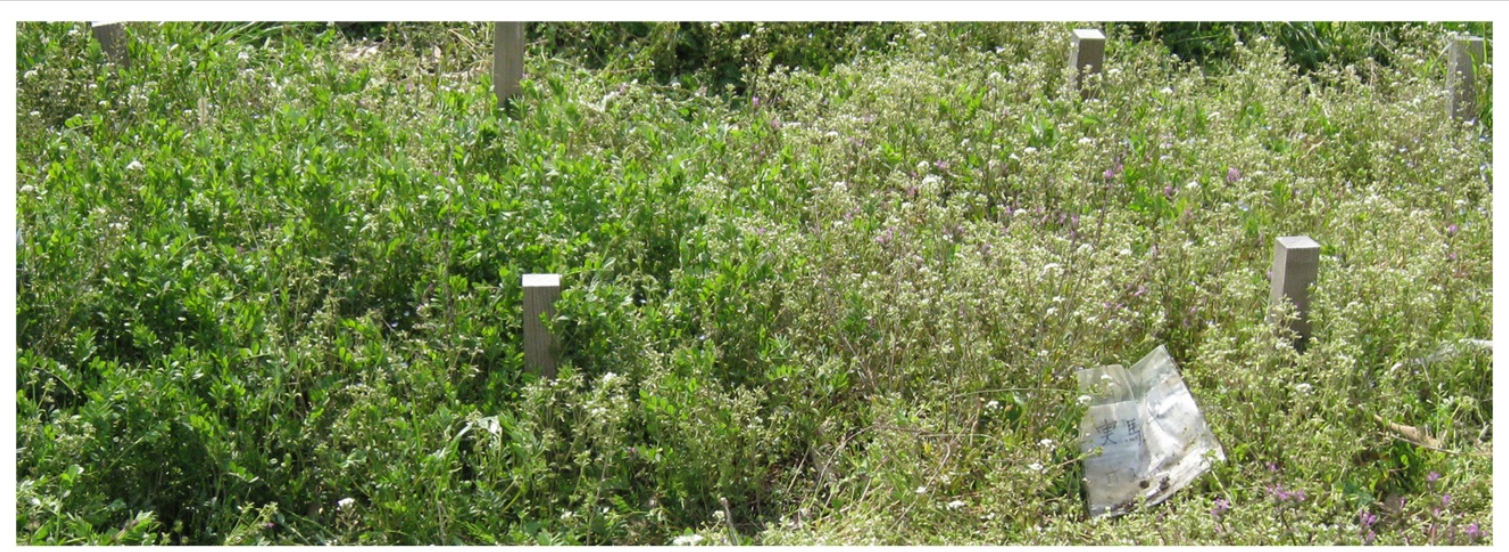

Figure 9 Field vegetation results after enhancing vertical infiltration and organic content recovery. Left side: macropore plot, right side: control plot. (Photo was taken from opposite side). 
Table 3 Weed flora of macropore and control plot after macropore treatment

\begin{tabular}{|c|c|c|c|c|}
\hline Scientific name & $\begin{array}{l}\text { No macropore } \\
\text { (grams of dry } \\
\text { matter }) /\left(\mathrm{m}^{2}\right)\end{array}$ & S.D. & $\begin{array}{l}\text { Macropore } \\
\text { (grams of dry } \\
\text { matter)/((m²) }\end{array}$ & S.D. \\
\hline Stellaria & 9.17 & 8.69 & 0.82 & 0.25 \\
\hline Poa annua & 9.72 & 0.84 & 5.74 & 2.34 \\
\hline Cerastium glomeratum & 25.83 & 4.74 & 24.82 & 9.43 \\
\hline Vicia sativa subsp. Nigra & 13.31 & 15.42 & 107.34 & 44.79 \\
\hline Equisetum arvense & 3.62 & 0.99 & 6.05 & 3.24 \\
\hline Lamium amplexicaule & 12.25 & 15.90 & 9.44 & 3.58 \\
\hline Capsella bursa-pastoris & 5.87 & 1.96 & 0.74 & 0.56 \\
\hline Calystegia japonica & 0.38 & 0.43 & 0.17 & 0.08 \\
\hline Veronica persica & 9.64 & 9.40 & 12.69 & 10.55 \\
\hline Erigeron annuus & 0.68 & 0.43 & 0.15 & - \\
\hline Cardamine scutata & 2.54 & 1.34 & N.D. & - \\
\hline Sonchus oleraceus & 0.30 & 0.16 & N.D. & - \\
\hline Lolium multiflorum Lam. & 0.76 & - & 0.27 & - \\
\hline Veronica arvensis & N.D. & - & 0.76 & - \\
\hline
\end{tabular}

S.D., standard deviation; N.D., not detected.

otherwise be washed away by surface water. In other words, we were not initially interested in vegetation growth, because we assumed it would take a longer time for the stripped plots to recover. However, the observed results exceeded our expectations, indicating a much faster vegetation recovery and a subsequent increase in organic carbon after just one experimental year. As a result, we are now considering a further development of this research aimed at demonstrating how improvements in drainage or enhanced infiltration can stimulate plant growth.

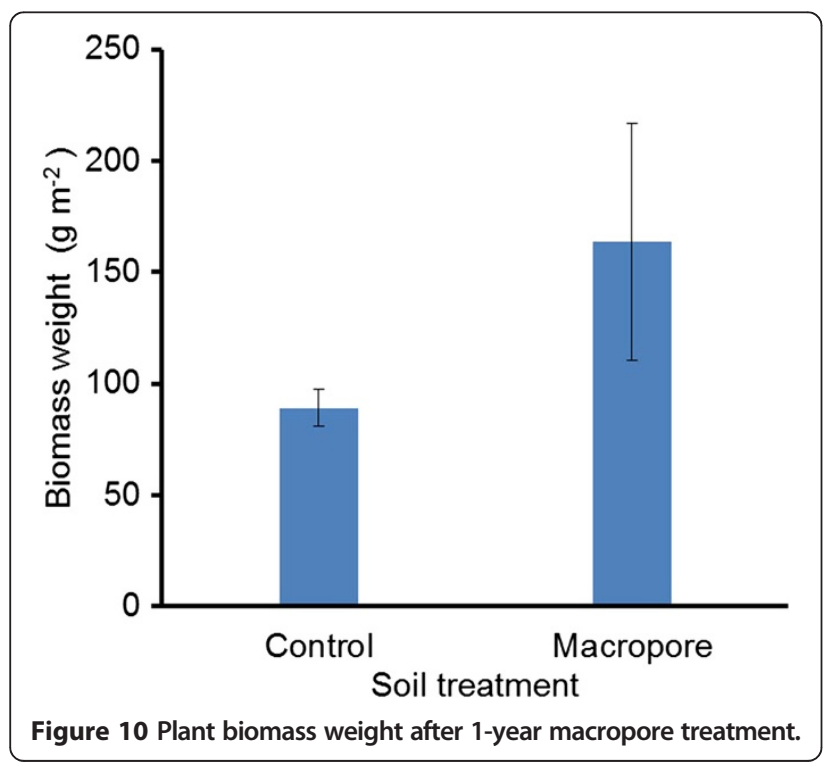

\section{Conclusions}

To help restore poorly drained soils and enhance their organic matter levels, vertical infiltration was improved via the introduction of an artificial macropore with fibrous fillings. In this study, we used a glass fiber as the filling material and examined its soil water-retention curve. Data from its field application were recorded using a soil water sensor, and the resultant plant biomass and total soil carbon were measured. The results of our experiments have allowed us to make the following conclusions:

1. The proposed artificial macropore system has clear advantages over poorly drained soils because the artificial macropore enhanced the vertical infiltration of the soil, while the fibrous fillings reinforced both the macropore structure and capillary drainage.

2. In our field test, rainfall was successfully introduced into the soil profile up to depths of $50 \mathrm{~cm}$, passing through $30 \mathrm{~cm}$, as detected by the soil water sensor. However, in our laboratory tests, the artificial macropore did not function effectively at $80 \mathrm{~mm} \cdot \mathrm{h}^{-1}$ rainfall levels, which are occurring with increasing frequency these days.

3. Plant biomass in the macropore plot was almost double that in the control plot, and soil carbon was found to have increased significantly in the macropore plot compared with the control plot. The artificial macropore successfully introduced surface water and organic matter into soils, which then stimulated vegetation growth.

4. The average TC increment in the macropore plot was calculated as $0.0012 \mathrm{~g}-\mathrm{C} \cdot \mathrm{g}_{\text {-soil }}{ }^{-1} \cdot \mathrm{yr}^{-1}$. The number was converted to $7.0 \mathrm{t}-\mathrm{C} \cdot \mathrm{ha}^{-1} \cdot \mathrm{yr}^{-1}$, which corresponded well with the increment for pasture management and afforestation.

This is the first time that an artificial macropore with glass fiber fillings has been used to promote the recovery of a degraded field. This material is durable, nonorganic, and industrially processed, so it can stay in the field for a long time. However, it would be preferable to use natural materials.

\section{Competing interests}

The authors' declared that they have no competing interests.

\section{Authors' contributions}

YM designed the 'artificial macropore' and framework of this study. AF conducted the laboratory and field experiment. KY collected and analyzed the plant biomass. YM wrote the manuscript. All authors read and discussed the draft manuscripts and approved the final manuscript.

\section{Authors' information}

Research fields of the authors: YM, soil physics/geophysics/environmental engineering; AF, soil physics/geophysics/environmental engineering; $K Y$, agronomy/plant sciences/environmental management. 


\section{Acknowledgements}

The authors are grateful to the MSC and BSc students who have supported the field experiments since their inception in 2008. This work was partially supported by the Japan Society for the Promotion of Science, NEXT program (GS021) 2011 to 2014 and a Grant-in-Aid for Scientific Research (B), 26292127, 2014 to 2016 and (C), 18510074, 2006 to 2008. The authors are also grateful to the Japanese Science and Technology Agency for support through their Research for Promoting Technological Seeds fund in 2009.

\section{Author details}

${ }^{1}$ Graduate School of Environmental and Life Science, Okayama University, 3-1-1 Tsushimanaka, Okayama 700-8530, Japan. ²Graduate School of Life and Environmental Science, Shimane University, Matsue, Japan.

Received: 2 July 2014 Accepted: 21 November 2014

Published online: 18 December 2014

\section{References}

Angers DA, Caron J (1998) Plant-induced changes in soil structure: processes and feedbacks. Biogeochemistry 42:55-72

Beven KJ, Germann PF (1982) Macropores and water flow in soils. Water Resour Res 18:1311-1325

Conant RT, Paustian K, Elliott ET (2001) Grassland management and conversion into grassland: effects on soil carbon. Ecol Appl 11:343-355

Eswaran H, Berg EVD, Reich P (1993) Organic carbon in soils of the world. Soil Sci Soc Am J 57:192-194

Flury M (1996) Experimental evidence of transport of pesticides through field soils: a review. J Environ Qual 25:25-45

Hillel D, Rosenzweig C (2009) Soil carbon and climate change. CSA News 54(6):4-11

IPCC (2007) Climate Change 2007: Mitigation of Climate Change. In: Metz B, Davidson OR, Bosch PR, Dave R, Meyer LA (eds) Contribution of Working Group III to the Fourth Assessment Report of the Intergovernmental Panel on Climate Change. Cambridge University Press, Cambridge, United Kingdom and New York, NY, USA

IPCC (2013) Climate Change 2013: The Physical Science Basis. In: Stocker TF, Qin D, Plattner G-K, Tignor M, Allen SK, Boschung J, Nauels A, Xia Y, Bex V, Midgley PM (eds.) Contribution of Working Group I to the Fifth Assessment Report of the Intergovernmental Panel on Climate Change. Cambridge University Press, Cambridge, United Kingdom and New York, NY, USA

Kiyono Y (1988) Analyses of factors affecting the dynamics of coverage and number of species in understories in Chamaecyparis obtusa plantations. J Jpn Forest Soc 70(10):455-460

Klute A, Dirksen C (1986) Hydraulic conductivities and diffusivity: laboratory methods. In: Kute A (ed) Methods of soil analysis. Part 1, Physical and mineralogical methods, 2nd edn. ASA-SSSA, Madison, WI, pp 687-734

Ministry of Agriculture, Forestry and Fisheries (2011) FY2011 annual report on food, agriculture and rural areas in Japan. Ministry of Agriculture, Forestry and Fisheries, Japan, Tokyo, pp 217-234

Miyamoto T, Kawahara M, Mori Y, Somura H, Ide J, Takahashi E, Yone Y, Suetsugu A (2013) Evaluation of management practices in forest soil environments using a multi-frequency electromagnetic sounding system. Jpn Soc Soil Phys 124:17-24

Mori Y, Higashi N (2009) Controlling solute transport processes in soils by using dual-porosity characteristics of natural soils. Colloids Surf A Physicochem Eng Asp 347(1-3):121-127

Mori Y, Hirai Y (2014) Effective vertical solute transport in soils by artificial macropore system. J Hazard Toxic Radioact Waste 18(2):1-7

Mori Y, Iwama K, Maruayma T, Mitsuno T (1999a) Discriminating the influence of soil texture and management-induced changes in macropore flow using soft X-rays. Soil Sci 164:467-482

Mori Y, Maruyama T, Mitsuno T (1999b) Soft X-ray radiography of drainage patterns of structured soils. Soil Sci Soc Am J 63(4):733-740

Mori Y, Takeda I, Fukushima A (2001) Soft X-ray radiography of structure-induced macropore flow in clayey soils. In: Adachi A, Fukue A (eds) Clay Science for Engineering. Balkema, Rotterdam, pp 297-302

Mori Y, Suetsugu A, Matsumoto Y, Fujihara A, Suyama K (2013) Enhancing bioremediation of oil-contaminated soils by controlling nutrient dispersion using dual characteristics of soil pore structure. Ecol Eng 51:237-243

Numata M, Yoshizawa N (1978) Weed flora of Japan -illustrated by colour-. Zennokyo, Tokyo
Oohara $\mathrm{H}$ (2007) The necessity for the research on the relationship between transition of forest floor vegetation accompanying thinning and function of soil and water conservation in artificial sugi (Cryptomeria japonica) forest. Bull FFPRI 6(2):127-134

Osawa K, Sakai K, Yoshinaga A, Tanaka T, Shimada M (2004a) Multi-point observation for suspended sediment movement in agricultural basin: studies on modeling of red soil runoff in Okinawa. Trans JSIDRE 229:101-108

Osawa K, Sakai K, Tanaka T, Yoshinaga A (2004b) Validation of USLE and WEPP for prediction of soil erosion at rainfall event: studies on modeling of red-soil runoff in Okinawa. Trans JSIDRE 232:43-50

The Japan Meteorological Agency (2013) Climate change monitoring report 2011. The Japan Meteorological Agency, Tokyo

Yamamoto T (2013) The effect of artificial macropores on the amount of organic matters in soils and plant biomass. Master thesis, Shimane University

Yukawa N, Onda Y (1995) The influences of understories on the infiltration capacities of Chamaecyparis obtusa plantations (I): experimental results using a mist type rainfall simulator. J Jpn Forest Soc 77(3):224-231

doi:10.1186/s40645-014-0030-5

Cite this article as: Mori et al:: Installing artificial macropores in degraded soils to enhance vertical infiltration and increase soil carbon content. Progress in Earth and Planetary Science 2014 1:30.

\section{Submit your manuscript to a SpringerOpen ${ }^{\odot}$ journal and benefit from:}

- Convenient online submission

- Rigorous peer review

- Immediate publication on acceptance

- Open access: articles freely available online

High visibility within the field

- Retaining the copyright to your article

Submit your next manuscript at $\gg$ springeropen.com 